\title{
$\mathrm{DEA}$ 와 맘퀴스트 생산성 지수를 활용한 $\mathrm{OECD}$ 국가간 의료서비스 효율성 분석
}

\author{
김지혜* · 김해수** · 임빛나** · 윤장혁**
}

\section{Analyzing the National Medical Service Efficiency of OECD Countries Using DEA and Malmquist Productivity Index}

Jihye Kim** Haesoo Kim** $\cdot$ Bitna Leem** J Janghyeok Yoon**

Health care that is considered to be one of the major factors for the quality of life is nowadays receiving a great deal of attention, and thus there is a growing need in Korea to identify the efficiency of national medical service and enhance the competitiveness. Although there exist studies on the medical service efficiency about general hospitals and local hospitals, they mostly deal with the efficiency problems from a domestic and regional perspective. In response, this paper analyzes the competitive efficiency of national medical service with respect to 16 OECD countries, by exploiting Data Envelopment Analysis (DEA) and Malmquist Productivity Index (MPI). Building on the DEA and MPI analysis results, this paper identifies the competitive position of Korean national medical service and suggests implications for the medical service improvement.

Keyword: National Medical Service, Efficiency Analysis, Service Competitiveness, Data Envelopment Analysis(DEA), Malmquist Productivity Index(MPI)

\footnotetext{
논문접수일 : 2012년 09월 27일 논문게재확정일 : 2012년 11월 22일

논문수정일(1차 : 2012년 11월 20일)

* 건국대학교 산업공학과, 제1저자

** 건국대학교 산업공학과

† 교신저자
} 


\section{1. 서 론}

삶의 질을 향상시키고자 하는 염원은 인류가 지 속적으로 추구해온 보편적인 가치이며, 그 중 건강 이라는 것은 삶의 질을 구성하는 가장 기본적인 요 소로서 중요하게 인식되고 있다[6, 29]. 현재 한국의 경우 국민소득 수준의 향상, 의료기술의 발전, 기대 수명의 증가, 인구의 고령화 등으로 의료서비스의 이 용 및 비용이 지속적으로 증가하는 추세에 있는데 [19], 이에 따라 최근에는 국민들이 의료서비스를 통 해 얼마나 높은 수준의 삶을 영위하며 행복하고 윤 택한 생활을 누리고 있는 지에 대한 관심이 고조되 고 있다[3]. 그럼에도 불구하고 국내의 의료서비스 공급역량은 이러한 의료수요의 증가추세에 비해 낮 은 수준이며 국민의 생활과 밀접한 연관을 갖고 있 는 보건·의료분야는 우리나라의 경제성장 수준에 비해 아직까지 국민에게 충분한 만족감을 안겨주지 못하고 있다는 평을 받고 있는 실정이다[2,13]. 이는 국민들에 대한 의료서비스 질적 우수성 또는 효율 성 차원의 문제로 연결될 수 있으며, 따라서 이러한 차원에 대한 국가적 차원의 분석은 생활수준 향상 에 따라 건강과 복지에 대해 관심을 기울이는 최근 의 경향에 있어서 중요한 문제이다.

의료서비스 성과의 효율성 측면에서는, DEA(Data Envelopment Analysis) 모형을 접목한 다양한 연 구들이 지금까지 시도되어 왔다. DEA는 비교 대상 들 간의 투입과 산출 결과를 활용하여 상대적 성과 를 비교분석할 수 있도록 정량화한 후 나아가 개선 해야 할 요소들과 개선의 가능성, 베스트 프렉티스 (Best Practice) 또는 벤치마킹(Benchmarking) 대 상을 제시할 수 있도록 한다는 측면에서 장점을 지닌 방법으로[22, 24], 공공기관 효율성 분석[10], 대학 기관 효율성 분석[17], 기업 경영 효율성 분석[20] 등 다양한 분야에 적용되어 왔다. 의료서비스와 관 련해서는, 투자 비용과 수익 간의 관계를 통한 지역 병원 또는 종합병원과 같은 의료기관들의 재무적 손 익 관계에 중점을 두거나[7, 12], 분석의 범주를 대 학병원간 또는 지방 의료기관과 같은 국내 의료기
관들에 대해 효율성을 분석함으로써 병원경영 상의 시사점을 도출하는 것을 주목적으로 한 연구들이 수행되어 왔다 $[5,16]$. 비록 지금까지 의료서비스 효 율성에 대한 다양한 연구들이 수행되어 왔지만, 저 자들의 조사에 따르면 국가적인 관점에서 한국의 의 료서비스 경쟁력을 선진국가들과 비교 분석하여 논 의점을 도출하는 연구는 미흡한 것으로 파악되었다. 국가적 관점에서의 의료서비스 효율성 및 생산성의 추이를 분석하는 것은 한국의 의료서비스 관련 정책 수립의 시사점 도출을 위한 프로세스의 중요한 단 계이다[7]. 따라서 본 연구는 병원경영의 효율성이 라는 논의를 확장하여 보건 및 의료 기관들을 통합 하는 의료서비스 기관들의 투입, 산출결과를 국가적 차원에서 바라보고 국가간의 의료서비스의 경쟁력 을 비교 분석하고자 한다.

이를 위해 본 연구에서는 $\mathrm{OECD}$ 헬스 데이터 $\left(\mathrm{He}^{-}\right.$ alth Data)와 DEA 모형을 이용하여 한국을 포함한 $\mathrm{OECD}$ 국가들 간의 연도별 의료서비스의 효율성을 비교분석한다. 또한 본 연구는 시간적인 흐름에 따 른 효율성 변화를 분석하는 지표인 MPI(Malmquist productivity growth Index, 맘퀴스트 생산성 지수) 를 이용하여 $\mathrm{OECD}$ 국가들에 대해 거시적 관점에서 의 의료서비스 효율성과 생산성의 변화 추이를 분 석한다. 본 연구의 결과는 효율성 관점에서 한국의 의료서비스 경쟁력의 위상을 파악한 후, 의료서비 스 향상을 위한 방향성을 도출한다는 점에서 의의를 지닌다. 따라서 본 연구는 추후 의료서비스 관련 정 책 수립 프로세스에서 국가간의 의료서비스 생산성 을 비교 분석하거나 한국 의료서비스의 현안을 도 출하는데 활용될 수 있을 것으로 기대된다.

본 연구는 먼저 제 2 장에서 국가간 의료서비스 생 산성을 비교분석하기 위한 방법인 $\mathrm{DEA}$ 와 MPI의 개념에 대해 설명하고, 제 3장에서는 분석 데이터 수집과 DEA에 사용된 투입, 산출요소들에 대해 설 명한다. 제 4장에서는 한국을 포함한 $\mathrm{OECD}$ 국가들 간의 연도별 생산성 분석과 시간의 흐름에 따른 생 산성의 변화 추이를 분석하고, 마지막 제 5 장에서는 논문을 요약하고 추후연구를 제시한다. 


\section{2. 이론적 배경}

\subsection{DEA 개념}

효율성(Efficiency)은 대체로 생산조직이 사용한 투입요소 대비 거두어 들인 산출물의 비율을 의미 하며 식 (1)과 같이 나타낼 수 있다[15, 27].

$$
\text { 효율성 }=\frac{\text { 산출물의 수량 }}{\text { 투입요소 사용량 }}
$$

그러나 일반적으로 투입 및 산출요소들간의 단위 가 상이하기 때문에 이러한 효율성을 객관적으로 측 정하기 위해 Charnes et al.[24]은 다수의 투입 및 산출요소의 가중치를 고려하여 주어진 $\mathrm{DMU}\left(\mathrm{Deci}^{-}\right.$ sion Making Unit, 의사결정 단위)의 상대적 효율성 을 측정할 수 있는 $\mathrm{DEA}$ 모형을 제시하였다. $\mathrm{DEA}$ 는 효율적인 $\mathrm{DMU}$ 의 개별적인 관찰에 초점을 두어 개 선 가능성에 대한 유용한 정보를 제공하기 때문에 각 $\mathrm{DMU}$ 를 상대적으로 평가하여 효율성을 측정함 과 동시에 개선안을 제시할 수 있다는 장점이 있다. $\mathrm{DEA}$ 는 최적 해를 구하는 수학적 방식에 따라 기본 적으로 투입중심(Input-oriented) 모형과 산출중심 (Output-oriented) 모형으로 나눌 수 있다[26]. 본 연 구에서는 DEA 모형의 분석결과를 통해 벤치마킹 (Benchmarking)이 가능한 국가 대상들을 찾고, 국 가간의 의료서비스 효율성을 비교분석하기 위해 가 장 널리 사용되는 $\mathrm{CCR}$ 모형과 $\mathrm{BCC}$ 모형을 사용한 다[4].

Charnes et al.[24]이 제시한 DEA의 가장 기본 모 형인 CCR 모형은 비영리적 의사결정단위를 대상으 로 다수의 투입물과 산출물을 고려하여 상대적 효율 성을 측정할 수 있다. 본 모형은 규모에 대한 보수 불변(Constant Returns to Scale, CRS)이라는 다수 의 산출물을 단일척도로 전환하는 기법의 선형분석 계획모형을 가정하므로, 효율성 점수가 규모의 효과 와 기술적 성과가 결합된 형태로 나타난다는 단점 이 있다. 투입지향형 $\mathrm{CCR}$ 모형에서는 다수 투입 대 비 다수 산출을 최대화 하는 것을 목적 함수로 하
며, 식 (2)와 같이 구성된다.

$$
\operatorname{Max} \frac{\sum_{\mathrm{r}=1}^{\mathrm{n}}\left(\mathrm{u}_{0}\right)\left(\mathrm{y}_{0}\right)}{\sum_{\mathrm{k}=1}^{\mathrm{m}}\left(\mathrm{v}_{0}\right)\left(\mathrm{x}_{0}\right)}
$$

$$
\mathrm{y}_{\mathrm{r}}=\text { 산출물 } \mathrm{r} \text { 의 벡터 }
$$

$\mathrm{x}_{\mathrm{k}}=$ 투입물 $\mathrm{k}$ 의 벡터

$\mathrm{u}_{\mathrm{r}}=$ 산출물 $\mathrm{r}$ 의 가중치

$\mathrm{y}_{\mathrm{k}}=$ 산출물 $\mathrm{k}$ 의 가중치

여기서 분모를 1 로 고정시키면 분자만 최대화하 는 선형계획모형의 목적함수가 되므로 $\mathrm{CCR}$ 모형은 식 (3)과 같이 표현된다. 각 투입요소와 산출요소의 가중치들은 0 보다 크다는 제약조건하에서 평가 대 상 $\mathrm{DMU}$ 의 측정치는 1 을 초과해서는 안되기 때문 에 가장 효율적인 $\mathrm{DMU}$ 의 점수는 1 이 된다[31].

$$
\begin{aligned}
& \operatorname{Max} \theta_{\mathrm{A}}=\sum_{\mathrm{r}=1}^{\mathrm{n}}\left(\mathrm{u}_{0}\right)\left(\mathrm{y}_{0}\right) \\
& \text { s.t } \sum_{\mathrm{k}=1}^{\mathrm{m}}\left(\mathrm{v}_{\mathrm{k} 0}\right)\left(\mathrm{x}_{\mathrm{k} 0}\right)=1 \\
& \sum_{\mathrm{r}=1}^{\mathrm{n}}\left(\mathrm{u}_{\mathrm{rj}}\right)\left(\mathrm{y}_{\mathrm{rj}}\right)-\sum_{\mathrm{k}=1}^{\mathrm{m}}\left(\mathrm{v}_{\mathrm{kj}}\right)\left(\mathrm{x}_{\mathrm{kj}}\right) \leq 0 \\
& \mathrm{u}_{\mathrm{r}}, \mathrm{v}_{\mathrm{k}} \geq \epsilon \\
& \epsilon=\text { non-archimedean 상수 } \\
& \mathrm{j}=1,2,3, \cdots, \mathrm{z} \\
& \mathrm{r}=1,2,3, \cdots, \mathrm{n} \\
& \mathrm{k}=1,2,3, \cdots, \mathrm{m}
\end{aligned}
$$

다음으로, $\mathrm{BCC}$ 모형은 $\mathrm{CCR}$ 모형의 한계를 극복 하기 위해 규모에 대한 수익가변(Variable Return to Scale, VRS)을 가정하여 순수 기술적 효율성을 찾 을 수 있고 규모에 대한 불변이라는 전제조건을 완 화함으로써 $\mathrm{CCR}$ 보다 현실적인 분석을 가능하게 했 다[22]. 결과적으로 $\mathrm{BCC}$ 모형은 규모의 효과를 배제 한 순수한 기술효율성을 나타내며 식 (4)와 같이 표현 된다. $\mathrm{BCC}$ 모형은 $\mathrm{CCR}$ 모형에 제약식을 추가한 형 태이므로 실행가능영역이 $\mathrm{CCR}$ 모형의 부분집합이 되어 $\mathrm{CCR}$ 모형에 비해 효율성 점수가 높은 $\mathrm{DMU}$ 가 더 많이 나타나게 된다[11]. 


$$
\begin{aligned}
& \operatorname{Max} \theta_{B}=\sum_{j=1}^{I}\left(y_{k j}\right)\left(u_{j}\right)+w \\
& \text { s.t } \sum_{i=1}^{I}\left(x_{k i}\right)\left(v_{i}\right)=1 \\
& \sum_{j=1}^{I}\left(y_{k j}\right)\left(v_{j}\right)-\sum_{i=1}^{I}\left(x_{k i}\right)\left(v_{j}\right)+w \leq 0 \\
& u_{r}, v_{k} \geq \epsilon \\
& k=1,2,3, \cdots, K \\
& i=1,2,3, \cdots, I \\
& j=1,2,3, \cdots, J \\
& W=\text { free }
\end{aligned}
$$

$\mathrm{DMU}$ 의 $\mathrm{CCR}$ 모형점수와 $\mathrm{BCC}$ 모형점수를 비교 하여 비효율의 원인이 $\mathrm{DMU}$ 자체의 문제인지 혹은 $\mathrm{DMU}$ 가 운영되는 조건이나 배경에 의한 것인지 조 사하기 위해서는 DMU의 규모효율성(Scale Efficiency)을 고려할 수 있다. 임의의 DMU가 CCR 모형 점수 및 $\mathrm{BCC}$ 모형점수에서 완전히 효율적이라면 이 것은 가장 생산적 규모의 크기로 운영되는 것을 의 미한다. 그러나 어떤 $\mathrm{DMU}$ 가 $\mathrm{BCC}$ 모형으로 완전 히 효율적이나 $\mathrm{CCR}$ 모형점수가 낮다면 이는 부분 적으로는 효율적으로 운영이 되나 $\mathrm{DMU}$ 규모의 크 기 때문에 전체적으로는 비효율적으로 운영됨을 의 미한다. 따라서 $\mathrm{CCR}$ 모형점수와 $\mathrm{BCC}$ 모형점수의 비율에 의하여 $\mathrm{DMU}$ 의 규모효율성이 결정된다. 규 모효율성은 식 (5)와 같이 표현될 수 있으며, $\mathrm{CCR}$ 모 형점수 $\left(\theta_{C C R}^{*}\right)$ 는 $\mathrm{BCC}$ 모형점수 $\left(\theta_{B C C}^{*}\right)$ 보다 작거나 같기 때문에 규모효율성 또한 1 보다 작거나 같다.

$$
\text { Scale Efficiency }(\mathrm{SE})=\frac{\theta_{C C R}^{*}}{\theta_{B C C}^{*}}
$$

\section{2 맘퀴스트 생산성 지수}

$\mathrm{DEA}$ 모형이 DMU들의 상대적인 효율성을 측정 할 수 있는 분석방법이라면, $\mathrm{MPI}$ 는 다른 시점간의 생 산성 변화 정도를 파악할 수 있도록 한다[25]. $\mathrm{t}$ 기와 $(\mathrm{t}+1)$ 기의 기술수준에 대한 생산성 변화를 나타내는 $\mathrm{MPI}$ 는 식 (6)와 같다.

$$
\begin{aligned}
& M\left(x^{t+1}, y^{t+1}, y^{t}, y^{t}\right) \\
& \quad=\left[\frac{D_{c}^{t}\left(x^{t}, y^{t}\right)}{D_{c}^{t}\left(x^{t+1}, y^{t+1}\right)} \times \frac{D_{c}^{t+1}\left(x^{t}, y^{t}\right)}{D_{c}^{t+1}\left(x^{t+1}, y^{t+1}\right)}\right] \frac{1}{2}
\end{aligned}
$$

식 (4)에서 $\mathrm{D}_{\mathrm{c}}^{\mathrm{t}}\left(\mathrm{x}^{\mathrm{t}}, \mathrm{y}^{\mathrm{t}}\right)$ 와 $\mathrm{D}_{\mathrm{c}}^{\mathrm{t}+1}\left(\mathrm{x}^{\mathrm{t}}, \mathrm{y}^{\mathrm{t}}\right)$ 는 각각 $\mathrm{t}$ 기와 $\mathrm{t}+1$ 기의 효율적 프론티어에서 투입요소, 산출요소 조 합에 대한 거리를 나타내고, $\mathrm{D}_{\mathrm{c}}$ 는 $\mathrm{CRS}$ 를 가정한 거 리함수를 표현한 것이다. MPI의 생산성변화의 요인을 분석하기 위한 식은 식 (7)과 같이 변환될 수 있다.

$$
\begin{aligned}
& M\left(x^{t+1}, y^{t+1}, y^{t}, y^{t}\right)=\frac{D_{c}^{t+1}\left(x^{t+1}, y^{t+1}\right)}{D_{c}^{t}\left(x^{t}, y^{t}\right)} \\
& \times\left[\frac{D_{c}^{t}\left(x^{t}, y^{t}\right)}{D_{c}^{t+1}\left(x^{t}, y^{t}\right)} \times \frac{D_{c}^{t}\left(x^{t+1}, y^{t+1}\right)}{D_{c}^{t+1}\left(x^{t+1}, y^{t+1}\right)}\right] \frac{1}{2} \\
& =\text { TECI } \times \text { TCI }
\end{aligned}
$$

위 식의 첫 번째 항은 두 기간 사이의 기술적 효 율성의 변화(Technical Efficiency Change, TEC)를 측정한 것이며 두 번째 항은 두 기간 사이의 기술 변화(Technical Change, TC)를 나타낸 것이다[30]. $\mathrm{TEC}$ 는 기술적 효율성 변화가 생산성 변화에 기여 한 정도를 나타내며, $\mathrm{TC}$ 는 기술혁신이 생산성 변동 에 기여한 정도를 나타낸다. 한편 TECI를 통해서 순 수효율성 변화(Pure Efficiency Change, PEC)와 규 모효율성 변화(Scale Efficiency Change, SEC)가 도 출된다. 따라서 $\mathrm{MPI}$ 는 식 (8)과 같이 순수 기술적 효 율성 변화, 규모 효율성 변화, 기술적 진보로 분해 하여 추정할 수 있다.

$$
\begin{aligned}
& \mathrm{M}\left(\mathrm{x}^{\mathrm{t}+1}, \mathrm{y}^{\mathrm{t}+1}, \mathrm{x}^{\mathrm{t}}, \mathrm{t}^{\mathrm{t}}\right)=\frac{\mathrm{D}_{\mathrm{v}}^{\mathrm{t}+1}\left(\mathrm{x}^{\mathrm{t}+1}, \mathrm{y}^{\mathrm{t}+1}\right)}{\mathrm{D}_{\mathrm{v}}^{\mathrm{t}}\left(\mathrm{x}^{\mathrm{t}}, \mathrm{y}^{\mathrm{t}}\right)} \\
& \times\left[\frac{\mathrm{D}_{\mathrm{v}}^{\mathrm{t}}\left(\mathrm{x}^{\mathrm{t}}, \mathrm{y}^{\mathrm{t}}\right)}{\mathrm{D}_{\mathrm{c}}^{\mathrm{t}}\left(\mathrm{x}^{\mathrm{t}}, \mathrm{y}^{\mathrm{t}}\right)} \div \frac{\mathrm{D}_{\mathrm{v}}^{\mathrm{t}+1}\left(\mathrm{x}^{\mathrm{t}+1}, \mathrm{y}^{\mathrm{t}+1}\right)}{\mathrm{D}_{\mathrm{c}}^{\mathrm{t}+1}\left(\mathrm{x}^{\mathrm{t}+1}, \mathrm{y}^{\mathrm{t}+1}\right)}\right]
\end{aligned}
$$

규모의 효율성 변화

$$
\begin{aligned}
& \times\left[\frac{D_{c}^{t}\left(x^{t+1}, y^{t+1}\right)}{D_{c}^{t}\left(x^{t}, y^{t}\right)} \times \frac{D_{c}^{t+1}\left(x^{t+1}, y^{t+1}\right.}{D_{c}^{t+1}\left(x^{t}, t^{t}\right)}\right]^{\frac{1}{2}} \\
& =\text { 기술변화 } \\
& =\text { PECI } \times \text { SECI } \times \text { TCI }
\end{aligned}
$$




\section{3. 분석자료}

\section{1 조사대상 및 $\mathrm{DMU}$ 설정}

본 연구에서는 국가간 의료서비스의 효율성을 파 악하기 위해 OECD health data(http://stats.oecd.org) 의 통계자료를 활용하였다. $\mathrm{DMU}$ 는 $\mathrm{OECD}$ 회원국 34개 국가들의 2005년에서 2009년에 해당하는 투입 - 산출 자료를 모두 수집한 뒤, 해당 자료에서 한국 의 데이터가 없는 것은 제외하여 선정하였다. 그리 고 정확한 효율성 비교분석을 위해 각 투입 · 산출 요소에 해당하는 자료가 완전한지를 고려하여 16 비 교대상국가(DMU)들을 선정하였다. 따라서 본 연구 에서 사용되는 $\mathrm{DMU}$ 는 오스트레일리아, 오스트리아, 벨기에, 체코, 에스토니아, 핀란드, 독일, 헝가리, 이 스라엘, 일본, 한국, 룩셈부르크, 멕시코, 노르웨이, 폴란드, 슬로베니아이다.

\section{2 투입 및 산출변수 선정과 자료 수집}

본 연구에서는 선행연구들의 적용사례와 각 변수 에 해당하는 자료의 적절성을 고려하여 투입요소 및 산출요소를 선정했다. <표 $1>$ 은 DEA 모형을 활용 한 의료·보건기관의 서비스 효율성 및 생산성을 분석한 주요 선행연구들을 요약한 것이며 각 연구 에서 사용된 투입 및 산출 요소들을 정리하고 있다.

$<$ 표 $1>$ 와 같이 국내외에서 $\mathrm{DEA}$ 를 활용한 의 료 - 보건기관의 서비스 생산성 및 경영 효율성을 측 정한 연구는 다양하게 수행되어 왔다. 하지만 대부 분의 연구들이 국제적인 관점에서 삶의 질과 관련 된 요소보다는 병원들간 또는 지역별 병원경영의 수익성과 관련된 요소들을 중심으로 효율성을 분석 하고 있다. 따라서 본 연구에서는 국가적인 차원의 의료서비스 투입·산출 요소들을 <표 $2>$ 와 같이 선정하여 활용한다.

〈표 1〉의료서비스 생산성과 관련 DEA 활용 선행연구

\begin{tabular}{|c|c|c|c|}
\hline 연구자 & 적용분야 & 투입변수 & 산출변수 \\
\hline Chang[23] & 공공병원 & $\begin{array}{l}\text { 의사, 간호사, 의료보조원, 일반 및 } \\
\text { 행정직원 }\end{array}$ & 외래환자수 및 입원환자 입원일수의 가중합 \\
\hline $\begin{array}{l}\text { Grsskopf } \\
\text { et al.[28] }\end{array}$ & 대학병원 & $\begin{array}{l}\text { 의사수, 간호사수, } \\
\text { 관리직원수, 운영병상수 }\end{array}$ & $\begin{array}{l}\text { 총입원환자수, 총외래환자수, 총응급환자수, } \\
\text { 총입원환자수술수, 총외래환자수술수 }\end{array}$ \\
\hline 이영범[14] & 공공병원 & 의사수, 간호사수, 행정직원수, 운영비 & 외래환자수, 입원환자수 \\
\hline 신종각[9] & 국립대학병원 & $\begin{array}{l}\text { 의사수, 간호사수, 일반직원수, } \\
\text { 의료비용, 운영 병상수, 인건비 }\end{array}$ & 입원환자수, 외래환자수, 의료수익, 자산총액 \\
\hline 김윤신[5] & 종합병원 & $\begin{array}{l}\text { 병상수, 의사수, 간호사수, 의료기사수, } \\
\text { 인건비, 재료비, 관리비 }\end{array}$ & $\begin{array}{l}\text { 외래환자수, 입원환자수, 수술건수, 입원수익, } \\
\text { 외래수익 }\end{array}$ \\
\hline
\end{tabular}

〈표 2〉 OECD 국가의 병원효율성 측정을 위한 투입 및 산출요소

\begin{tabular}{cll}
\hline 평가 요소 & \multicolumn{2}{c}{ 세부기준 } \\
\hline \hline \multirow{3}{*}{ 투입물 } & 의료지출 & 의료서비스의 금전적인 요소(달러/1인) \\
\cline { 2 - 3 } & 병원 & 전문적인 의료서비스가 제공되는 장소(기관/백만명) \\
\cline { 2 - 3 } & 병상 & 병원의 규모를 보여주는 대표변수(베드 수/천명) \\
\cline { 2 - 3 } & 보건\&사회인력 & 의료인력을 제외한 보건\&사회인력(인원 수/천명) \\
\cline { 2 - 3 } & 현직의사 & 의료인력 중 대표적인 의료서비스 제공자(인원 수/천명) \\
\hline \multirow{2}{*}{ 산출물 } & 기대수명 & 삶의 질을 객관적으로 판단하는 기준(년/1인) \\
\cline { 2 - 3 } & 환자의 진료 & 보건 및 의료 서비스의 접근성(횟수/1인) \\
\hline
\end{tabular}


선정된 투입 및 산출요소들은 기존 문헌 연구결 과를 근거로 하여 본 연구의 목적에 적합한 것들을 선정하여 사용한다. 먼저 투입변수로 인구단위를 고 려하여 연도별 의료지출, 병원 수, 병상 수, 보건\&사 회 인력 수, 현직 의사 수를 사용하고 산출변수로는 연도별 기대수명, 환자의 진료횟수를 사용하였다. 투 입변수에 의료지출을 변수로 선정한 이유는 의료서 비스의 효율성을 제고하는 금전적 요소로 작용한다 고 판단했기 때문이다. 그리고 병원은 의료서비스가 제공되는 대표적인 장소이고, 병상은 병원의 규모 를 나타내므로 선정되었다. 다음으로 의사와 보건\& 사회인력은 의료서비스의 제공자로서 투입요소로 사 용될 수 있을 것으로 판단된다[21]. 산출변수에 기대 수명을 채택한 이유는 삶의 질을 객관화하는 중요 한 척도 중의 하나이자 의료서비스의 최종적인 결 과가 바로 기대수명이기 때문이며 $[1,8]$, 환자 일인 당 연평균 진료 횟수의 경우 환자가 의사를 통하여 평소에 보건 및 의료서비스를 받을 수 있는 접근성 파악의 중요한 요소이기 때문에 선정하였다[18].

<표 3>은 2005년부터 2009년까지의 OECD health data를 기반으로 $\mathrm{OECD}$ 회원국 16 개 국가들의 보 건서비스 효율성을 측정하는데 사용된 연도별 투입 - 산출변수의 기술 통계량을 나타낸 것이다.

〈표 3〉5개년 평균 투입 및 산출변수의 기술통계량

\begin{tabular}{ccccc}
\hline 투입·산출변수 & 평균 & 표준편차 & 최소값 & 최대값 \\
\hline \hline 의료지출 & 2603 & 1267 & 731 & 5348 \\
\hline 병원 & 34.59 & 17.92 & 13.67 & 70.64 \\
\hline 병상 & 6.281 & 2.674 & 1.67 & 14.08 \\
\hline 보건\&사회인력 & 41.68 & 22.71 & 10.93 & 109.48 \\
\hline 현직의사 & 2.906 & 0.732 & 1.63 & 4.68 \\
\hline 기대수명 & 78.539 & 2.781 & 72.7 & 83 \\
\hline 환자의 진료 & 7.661 & 3.097 & 2.6 & 13.7 \\
\hline
\end{tabular}

\section{4. 분석 결과}

\section{1 정태적 분석}

본 연구에서는 먼저 $\mathrm{OECD}$ 국가별로 단기적인
의료서비스의 효율성을 파악하기 위해 정태적 분석 을 하며, 산출량을 유지하고 투입량의 변화에 따른 효율성의 변화를 알아보기 위해 투입기준 CCR 모 형과 투입기준 $\mathrm{BCC}$ 모형을 사용한다. 본 논문에서 는 2005년에서 2009년까지의 5개 년도에 대해 조사 하며 의료서비스 생산성 현황을 알아보기 위한 분 석을 수행한다.

우선 투입중심 $\mathrm{CCR}$ 효율성 분석결과는 <표 4> 와 같다. 나타난 바와 같이 헝가리, 이스라엘, 한국, 멕시코, 노르웨이, 폴란드, 슬로베니아는 5 개년 동 안 $\mathrm{CCR}$ 효율성 점수가 1 로 우수하여 효율성 관점 에서 개선의 필요가 없는 것으로 파악된다. 체코는 2006년과 2007년 효율성 점수가 1이었으나 그 이후 계속해서 점수의 하락세를 보이고 있으며, 에스토 니아는 2005년 효율성이 1로 1위였으나 그 이후 계 속해서 $\mathrm{CCR}$ 모형의 점수가 급속하게 감소하는 경 향을 보였다. 오스트리아는 5년 동안 꾸준히 효율성 순위가 16 위로, 조사한 $\mathrm{OECD}$ 국가들 중 가장 낮은 효율성을 보였다. 오스트레일리아, 벨기에, 핀란드, 독일, 룩셈부르크는 순위 변동이 미미하지만 지속 적으로 효율성 점수가 조금씩 증가하였다.

한편, <표 4>의 가장 오른쪽 열은 2009년을 기준 으로 하여 투입방향 CCR 모형을 바탕으로 한 벤치 마킹 대상과 Lambda 값을 보여준다. DEA 모형이 제시하는 벤치마킹 대상과 Lambda 값을 이용하면 비효율적인 $\mathrm{DMU}$ 의 효율화 방안을 모색하는데 도 움이 되기 때문에 이를 분석하는 것은 큰 의의가 있다. 한국을 벤치마킹할 수 있는 국가들로는 오스트 레일리아, 벨기에, 핀란드, 독일, 일본, 룩셈부르크가 있으며, 그 중 특히 일본은 $100 \%$ 로 한국을 가장 큰 정도의 비율로 벤치마킹 하여야 최적의 의료서비스 효율성을 가지는 국가로 발전할 수 있다고 해석된다. 가장 많은 나라들을 벤치마킹한 나라는 오스트리아 와 독일이며 공통적으로 벤치마킹의 대상이 된 나 라는 $\mathrm{CCR}$ 효율성 점수가 높게 나온 헝가리, 멕시코, 슬로베니아였다. CCR 효율성 점수가 1 이 아닌 다 른 국가들은 벤치마킹 대상으로 파악된 국가들의 의 료서비스 현황을 파악하여 자신들의 의료서비스 제 
〈표 4〉CCR 효율성 분석결과

\begin{tabular}{|c|c|c|c|c|c|c|c|c|c|c|c|}
\hline \multirow{2}{*}{ DMU } & \multicolumn{2}{|c|}{2005} & \multicolumn{2}{|c|}{2006} & \multicolumn{2}{|c|}{2007} & \multicolumn{2}{|c|}{2008} & \multicolumn{3}{|c|}{2009} \\
\hline & CCR & 순위 & $\mathrm{CCR}$ & 순위 & CCR & 순위 & CCR & 순위 & CCR & 순위 & 벤치마킹 \\
\hline Australia & 0.864 & 11 & 0.887 & 11 & 0.957 & 9 & 0.984 & 8 & 0.989 & 8 & $\begin{array}{l}\text { Israel(0.684); } \\
\text { Korea(0.123); } \\
\text { Mexico(0.194) }\end{array}$ \\
\hline Austria & 0.599 & 16 & 0.614 & 16 & 0.619 & 16 & 0.586 & 16 & 0.578 & 16 & $\begin{array}{l}\text { Hungary }(0.124) ; \\
\text { Israel(0.190); } \\
\text { Mexico }(0.122) ; \\
\text { Slovenia }(0.564)\end{array}$ \\
\hline Belgium & 0.817 & 13 & 0.825 & 13 & 0.847 & 13 & 0.838 & 13 & 0.868 & 12 & $\begin{array}{c}\text { Hungary }(0.138) ; \\
\text { Korea }(0.032) ; \\
\text { Slovenia }(0.830)\end{array}$ \\
\hline Czech Republic & 0.996 & 9 & 1.000 & 1 & 1.000 & 1 & 0.981 & 9 & 0.932 & 9 & $\begin{array}{c}\text { Hungary(0.762); } \\
\text { Israel(0.238) }\end{array}$ \\
\hline Estonia & 1.000 & 1 & 0.975 & 9 & 0.953 & 10 & 0.869 & 12 & 0.841 & 13 & $\begin{array}{c}\text { Hungary(0.376); } \\
\text { Mexico(0.624) }\end{array}$ \\
\hline Finland & 0.657 & 14 & 0.683 & 14 & 0.714 & 14 & 0.744 & 14 & 0.769 & 14 & $\begin{array}{c}\text { Korea }(0.388) \\
\text { Mexico }(0.456) ; \\
\text { Slovenia }(0.156)\end{array}$ \\
\hline Germany & 0.604 & 15 & 0.621 & 15 & 0.637 & 15 & 0.640 & 15 & 0.664 & 15 & $\begin{array}{c}\text { Hungary }(0.144) ; \\
\text { Korea(0.204); } \\
\text { Mexico(0.129); } \\
\text { Slovenia(0.523) }\end{array}$ \\
\hline Hungary & 1.000 & 1 & 1.000 & 1 & 1.000 & 1 & 1.000 & 1 & 1.000 & 1 & Hungary(1.000) \\
\hline Israel & 1.000 & 1 & 1.000 & 1 & 1.000 & 1 & 1.000 & 1 & 1.000 & 1 & Israel(1.000) \\
\hline Japan & 0.919 & 10 & 0.894 & 10 & 0.859 & 11 & 0.891 & 10 & 0.909 & 10 & Korea(1.000) \\
\hline Korea & 1.000 & 1 & 1.000 & 1 & 1.000 & 1 & 1.000 & 1 & 1.000 & 1 & Korea(1.000) \\
\hline Luxembourg & 0.826 & 12 & 0.841 & 12 & 0.848 & 12 & 0.870 & 11 & 0.879 & 11 & $\begin{array}{l}\text { Korea(0.104); } \\
\text { Mexico(0.095); } \\
\text { Slovenia(0.825) }\end{array}$ \\
\hline Mexico & 1.000 & 1 & 1.000 & 1 & 1.000 & 1 & 1.000 & 1 & 1.000 & 1 & Mexico(1.000) \\
\hline Norway & 1.000 & 1 & 1.000 & 1 & 1.000 & 1 & 1.000 & 1 & 1.000 & 1 & Norway(1.000) \\
\hline Poland & 1.000 & 1 & 1.000 & 1 & 1.000 & 1 & 1.000 & 1 & 1.000 & 1 & Poland(1.000) \\
\hline Slovenia & 1.000 & 1 & 1.000 & 1 & 1.000 & 1 & 1.000 & 1 & 1.000 & 1 & Slovenia(1.000) \\
\hline
\end{tabular}

도 및 프로세스를 개선함으로써 국가 의료서비스 효율성을 개선할 수 있을 것으로 기대된다.

다음으로 투입중심 $\mathrm{BCC}$ 효율성 평가는 <표 5> 와 같이 도출된다. 표를 참고했을 때 2009년 기준 $\mathrm{OECD} 16$ 개 국가들의 $\mathrm{BCC}$ 모형의 평균 효율성 점 수는 0.939 로 $\mathrm{CCR}$ 모형의 결과보다 월등히 높은 점
수를 보였고, 효율성 점수는 오스트레일리아, 벨기 에, 헝가리, 이스라엘, 일본, 한국 등이 1 로 공동 1 위 이며 가장 효율적으로 나타났다. 오스트레일리아, 체코, 헝가리, 이스라엘, 일본, 한국, 멕시코, 노르웨 이, 폴란드, 슬로베니아, 폴란드는 2005년부터 2009 까지 효율성이 모두 1 로 나왔으며, 반면에 오스트리 
〈표 5〉BCC 효율성 분석결과

\begin{tabular}{|c|c|c|c|c|c|c|c|c|c|c|c|}
\hline \multirow{2}{*}{$\mathrm{DMU}$} & \multicolumn{2}{|c|}{2005} & \multicolumn{2}{|c|}{2006} & \multicolumn{2}{|c|}{2007} & \multicolumn{2}{|c|}{2008} & \multicolumn{3}{|r|}{2009} \\
\hline & $\mathrm{BCC}$ & 순위 & $\mathrm{BCC}$ & 순위 & $\mathrm{BCC}$ & 순위 & $\mathrm{BCC}$ & 순위 & $\mathrm{BCC}$ & 순위 & 벤치마킹 \\
\hline Australia & 1.000 & 1 & 1.000 & 1 & 1.000 & 1 & 1.000 & 1 & 1.000 & 1 & Australia(1.000) \\
\hline Austria & 0.686 & 16 & 0.702 & 15 & 0.742 & 15 & 0.704 & 16 & 0.607 & 16 & $\begin{array}{c}\text { Israel }(0.439) ; \\
\text { Japan }(0.043) ; \\
\text { Korea }(0.049) ; \\
\text { Luxembourg( }(0.036) ; \\
\text { Slovenia }(0.433)\end{array}$ \\
\hline Belgium & 0.969 & 12 & 0.942 & 12 & 1.000 & 1 & 0.981 & 12 & 1.000 & 1 & Belgium(1.000) \\
\hline Czech Republic & 1.000 & 1 & 1.000 & 1 & 1.000 & 1 & 1.000 & 1 & 1.000 & 1 & Czech Republic(1.000) \\
\hline Estonia & 1.000 & 1 & 0.993 & 11 & 0.972 & 12 & 0.873 & 13 & 0.845 & 14 & $\begin{array}{c}\text { Hungary(0.345); } \\
\text { Korea }(0.029) ; \\
\text { Mexico(0.625) }\end{array}$ \\
\hline Finland & 0.742 & 14 & 0.770 & 14 & 0.816 & 14 & 0.845 & 14 & 0.876 & 13 & $\begin{array}{c}\text { Australia(0.344); } \\
\text { Korea(0.401); } \\
\text { Mexico(0.096); } \\
\text { Slovenia }(0.160)\end{array}$ \\
\hline Germany & 0.688 & 15 & 0.678 & 16 & 0.737 & 16 & 0.716 & 15 & 0.699 & 15 & $\begin{array}{c}\text { Israel }(0.229) ; \\
\text { Japan }(0.046) ; \\
\text { Korea }(0.257) ; \\
\text { Luxembourg }(0.107) ; \\
\text { Slovenia }(0.360)\end{array}$ \\
\hline Hungary & 1.000 & 1 & 1.000 & 1 & 1.000 & 1 & 1.000 & 1 & 1.000 & 1 & Hungary(1.000) \\
\hline Israel & 1.000 & 1 & 1.000 & 1 & 1.000 & 1 & 1.000 & 1 & 1.000 & 1 & Israel(1.000) \\
\hline Japan & 1.000 & 1 & 1.000 & 1 & 1.000 & 1 & 1.000 & 1 & 1.000 & 1 & $\operatorname{Japan}(1.000)$ \\
\hline Korea & 1.000 & 1 & 1.000 & 1 & 1.000 & 1 & 1.000 & 1 & 1.000 & 1 & Korea(1.000) \\
\hline Luxembourg & 0.941 & 13 & 0.885 & 13 & 0.942 & 13 & 1.000 & 1 & 1.000 & 1 & Luxembourg(1.000) \\
\hline Mexico & 1.000 & 1 & 1.000 & 1 & 1.000 & 1 & 1.000 & 1 & 1.000 & 1 & Mexico(1.000) \\
\hline Norway & 1.000 & 1 & 1.000 & 1 & 1.000 & 1 & 1.000 & 1 & 1.000 & 1 & Norway(1.000) \\
\hline Poland & 1.000 & 1 & 1.000 & 1 & 1.000 & 1 & 1.000 & 1 & 1.000 & 1 & Poland(1.000) \\
\hline Slovenia & 1.000 & 1 & 1.000 & 1 & 1.000 & 1 & 1.000 & 1 & 1.000 & 1 & Slovenia(1.000) \\
\hline
\end{tabular}

아와 독일은 2005년부터 2009년까지 BCC 효율성이 모두 0.8 에 못 미치는 점수로 효율성이 가장 낮았다. 룩셈부르크는 2005년과 2007년에는 0.941의 효율성 을 가졌었지만 2008년부터는 1로 효율성이 향상되 었고, 핀란드는 순위 변동이 크게 일어나지는 않았 지만 2005년 0.742에서 2009년 0.876로 지속적으로 꾸준히 $\mathrm{BCC}$ 효율성이 증가하였다. 그에 반해 에스 토니아는 2005년도에 효율성이 1이였지만 점차 감
소하여 2009년에는 효율성 점수가 0.845 이었다. $\mathrm{BCC}$ 모형을 기반으로 한 분석 결과, 가장 많은 나라들을 벤치마킹한 나라는 독일과 오스트리아이며 CCR 효 율성 분석 결과와 비교했을 때, 벤치마킹 대상으로 일본이 추가되었다. 한편 $\mathrm{BCC}$ 모형의 결과는 $\mathrm{CCR}$ 모형의 결과에 비해 효율적인 국가가 많아 $\mathrm{CCR}$ 모 형의 효율성 순위와는 다소 차이가 있었으며, 따라 서 효율성에 대한 판별력은 더 낮아졌다. 
〈표 6〉규모효율성 분석결과

\begin{tabular}{ccccccccccc}
\hline & \multicolumn{2}{c}{2005} & \multicolumn{2}{c}{2006} & \multicolumn{2}{c}{2007} & \multicolumn{2}{c}{2009} \\
\cline { 2 - 11 } 국가 & SE & 순위 & SE & 순위 & SE & 순위 & SE & 순위 & SE & 순위 \\
\hline \hline Australia & 0.864 & 15 & 0.887 & 13 & 0.957 & 10 & 0.984 & 9 & 0.989 & 9 \\
\hline Austria & 0.874 & 14 & 0.876 & 16 & 0.834 & 16 & 0.833 & 16 & 0.952 & 10 \\
\hline Belgium & 0.843 & 16 & 0.876 & 15 & 0.847 & 15 & 0.854 & 15 & 0.868 & 16 \\
\hline Czech Republic & 0.996 & 9 & 1.000 & 1 & 1.000 & 1 & 0.981 & 10 & 0.932 & 12 \\
\hline Estonia & 1.000 & 1 & 0.981 & 9 & 0.981 & 9 & 0.995 & 8 & 0.996 & 8 \\
\hline Finland & 0.885 & 11 & 0.886 & 14 & 0.875 & 12 & 0.880 & 13 & 0.878 & 15 \\
\hline Germany & 0.878 & 12 & 0.917 & 11 & 0.864 & 13 & 0.894 & 11 & 0.951 & 11 \\
\hline Hungary & 1.000 & 1 & 1.000 & 1 & 1.000 & 1 & 1.000 & 1 & 1.000 & 1 \\
\hline Israel & 1.000 & 1 & 1.000 & 1 & 1.000 & 1 & 1.000 & 1 & 1.000 & 1 \\
\hline Japan & 0.919 & 10 & 0.894 & 12 & 0.859 & 14 & 0.891 & 12 & 0.909 & 13 \\
\hline Korea & 1.000 & 1 & 1.000 & 1 & 1.000 & 1 & 1.000 & 1 & 1.000 & 1 \\
\hline Luxembourg & 0.877 & 13 & 0.950 & 10 & 0.900 & 11 & 0.870 & 14 & 0.879 & 14 \\
\hline Mexico & 1.000 & 1 & 1.000 & 1 & 1.000 & 1 & 1.000 & 1 & 1.000 & 1 \\
\hline Norway & 1.000 & 1 & 1.000 & 1 & 1.000 & 1 & 1.000 & 1 & 1.000 & 1 \\
\hline Poland & 1.000 & 1 & 1.000 & 1 & 1.000 & 1 & 1.000 & 1 & 1.000 & 1 \\
\hline Slovenia & 1.000 & 1 & 1.000 & 1 & 1.000 & 1 & 1.000 & 1 & 1.000 & 1 \\
\hline
\end{tabular}

다음으로 규모 효율성 평가는 <표 6>과 같이 도 출되었다. 2009년 기준으로 헝가리, 이스라엘, 한국, 멕시코, 노르웨이, 폴란드, 슬로베니아가 규모효율 성이 1 로 가장 높았고, 이 중 헝가리, 이스라엘, 한 국, 멕시코, 노르웨이, 폴란드, 슬로베니아 는 2005 년부터 2009년 까지 규모 효율성이 모두 1로 유지 되었다. 이러한 나라들은 규모 효과를 잘 이용하여 효율적 보건서비스 제공 했다고 볼 수 있다. 오스트 레일리아 같은 경우에는 규모효율성이 1 은 아니지 만 2005년부터 2009년까지 꾸준히 증가한 것으로 보아 점차 규모 효과의 이용성이 높아졌다고 볼 수 있다. 그에 반해 체코, 에스토니아, 일본, 핀란드 같 은 경우에는 2005년에 비해 2009년의 규모 효율성이 낮게 나왔으며 벨기에, 핀란드, 룩셈부르크, 오스트 리아 같은 나라들은 규모 효율성이 낮게 나왔는데, 이는 $\mathrm{BCC}$ 점수에 비해 $\mathrm{CCR}$ 점수가 비효율적인 경 우로, 내부적으로는 효율적이지만 규모의 효율화를 이루어내지 못했다고 볼 수 있다. 따라서 규모효율 성이 비교적 낮게 나타난 나라들은 효율적 보건서
비스를 위해 운영 투입변수들을 이상적 규모로 맞 춰야 할 것이다.

위의 분석결과를 기반으로, OECD 16 개국의 2009 년도 $\mathrm{DEA}$ 분석결과를 요약하면 [그림 1]과 같게 나타난다.

\section{2 동태적 분석}

제 4.1절에서 시행한 $\mathrm{DEA}$ 분석방법은 각 연도별 효율성만을 측정할 수 있고 $\mathrm{DMU}$ 의 생산성 변화 추이를 살펴보는데 한계가 있다. 따라서 본 연구에 서는 2005년부터 2009년까지의 생산성 변화의 정도 를 측정하기 위해 $\mathrm{MPI}$ 와 관련 지수들을 도출하였 다. <표 7>은 기간별 평균 생산성 변화를 보여준 다. 이 때, 각 생산성 지수값은 변화율을 의미하므 로 기하평균을 사용하여 생산성 변화의 평균값을 도출하였다. 기간 1은 2005 2006년, 기간 2는 2006 2007년, 기간 3은 2007 2008년, 기간 4는 2008 2009년이다. 


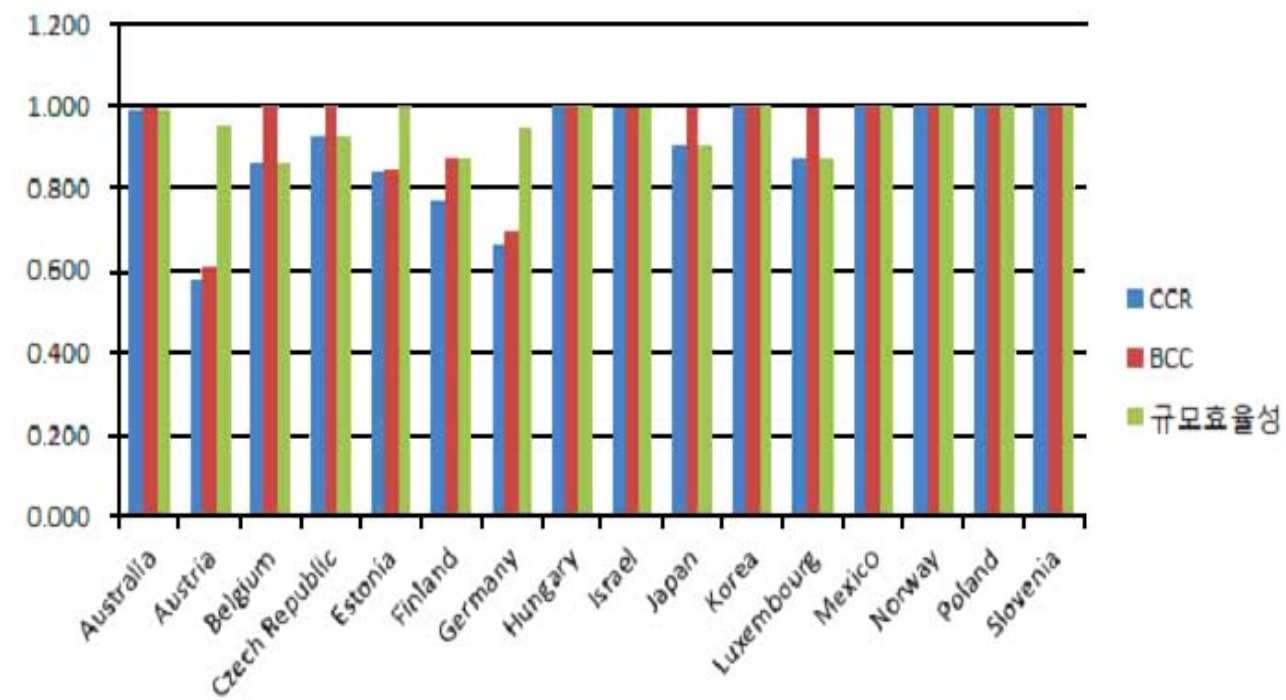

[그림 1] 2009년 기준 DMU별 DEA 분석 결과

〈표 7〉 기간별 평균 생산성 지수

\begin{tabular}{cccccc}
\hline 기간 & TECI & TCI & PECI & SECI & TFPI \\
\hline \hline 1 & 1.005 & 0.988 & 0.995 & 1.010 & 0.993 \\
\hline 2 & 1.031 & 0.926 & 1.030 & 1.001 & 0.954 \\
\hline 3 & 1.035 & 0.934 & 1.026 & 1.008 & 0.967 \\
\hline 4 & 1.005 & 0.988 & 0.995 & 1.009 & 0.993 \\
\hline 평균 & 1.019 & 0.959 & 1.012 & 1.007 & 0.977 \\
\hline
\end{tabular}

<표 7>을 보면 MPI를 기간별로 비교하였을 때 증감 추이가 미약하게나마 계속 나타나는 경향을 보 였는데 기간 2, 즉 2006 2007년에서는 TFPI가 4.6\% 로 5 개년 구간 중 가장 많이 하락하였으나 기간 4 인 2008 2009년에 이르러서는 $0.7 \%$ 로 감소의 정도 가 줄어들었음을 알 수 있다. 전체적으로 봤을 때 $\mathrm{DMU}$ 들의 $\mathrm{TFPI}$ 는 평균적으로 $2.3 \%$ 가 감소하였는 데 이는 $\mathrm{TECI}(1.019)$ 에 비해 $\mathrm{TCI}(0.959)$ 가 더 영향 을 미쳤기 때문이다. 특히 TCI의 감소에는 기간 2에 서 $7.4 \%$, 기간 3 에서 $6.6 \%$ 로 비교적 크게 하락하여 TFPI의 상향을 억제하고 있다. 즉 5년간 전체적으 로 기술의 퇴보가 발생하여 전체적인 MPI 하락에 크게 작용했음을 알 수 있다. 한편 TECI는 지속적 으로 평균 $1.9 \%$ 가 증가하였는데 이는 5 년 동안 평
균적으로 $\mathrm{PECI}$ 가 $1.2 \%, \mathrm{SECI}$ 가 $0.7 \%$ 씩 상승되었기 때문이다.

[그림 2]는 국가별 평균 생산성지수를 개략적으 로 그래프를 통해 나타낸 것이다. 전체적으로 5개년 동안 밨을 때 가장 높은 생산성 지수를 나타낸 나 라는 슬로베니아, 노르웨이, 룩셈부르크, 벨기에, 일 본 순이며 이는 $\mathrm{DEA}$ 분석의 $\mathrm{CCR}$ 모형 분석결과와 는 조금 다르게 나타났다. 슬로베니아와 노르웨이 의 경우 $\mathrm{CCR}$ 효율성 순위도 1 위로 정태적으로나 동태적으로나 의료서비스의 효율성이 좋다고 보여 진다. 하지만 룩셈부르크, 벨기에, 일본은 앞서 분석 한 $\mathrm{CCR}$ 점수의 5 개년 순위가 12 위, 13 위, 10 위 등 으로 하위권에 속한 나라였다. 따라서 이들 국가는 특정 년도 별로 각 나라의 의료서비스를 바라보았 을 때, 다른 $\mathrm{OECD}$ 국가에 비해서 상대적으로 낮은 효율성 점수지만 연도 기간별로 보면 높은 생산성 향상을 보여왔다고 해석할 수 있다.

조금 더 세부적으로 분석하기 위해서 국가별 평 균 생산성 지수를 나타낸 결과값은 <표 8>과 같다. $<$ 표 8>은 생산성 변화에 기하평균을 이용하여 각 나라별 생산성 비교를 나타낸 것이다. 슬로베니아 가 가장 높은 생산성 증가율인 $4.2 \%$ 를 보여주며, 


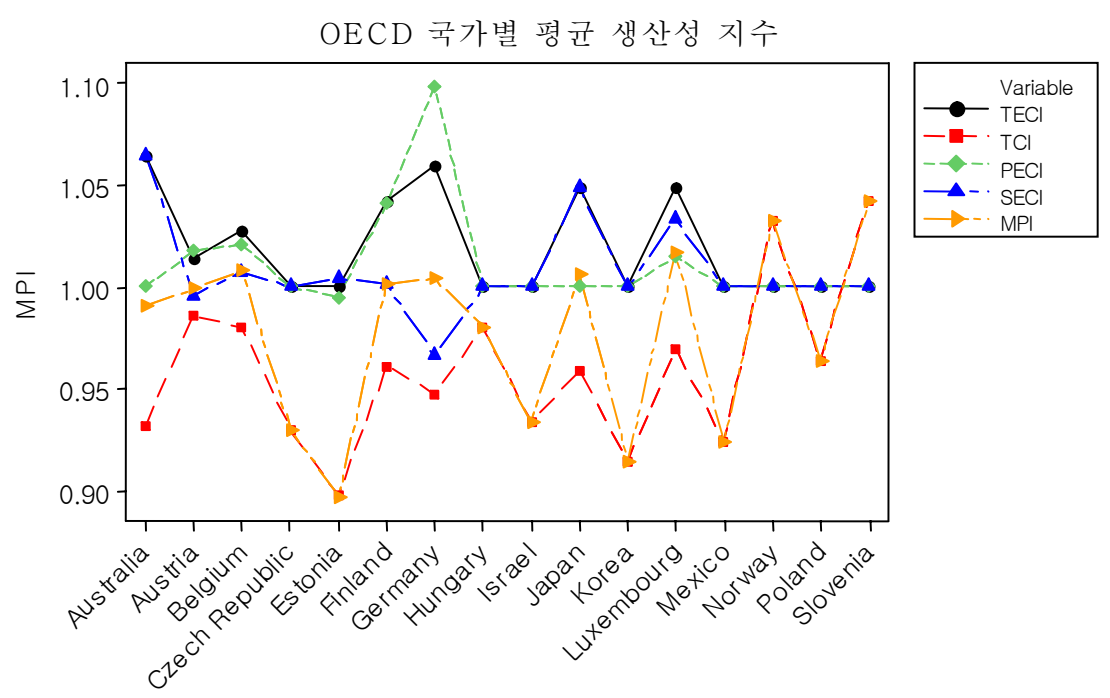

[그림 2] OECD 국가별 평균 MPI 지수

이는 TCI(1.042) 즉 기술적인 혁신에 의해 효율성이 향상된 것으로 보인다. 반면 가장 낮은 생산성 지수 를 나타낸 나라는 에스토니아이며 $10.3 \%$ 의 감소율 을 보여주는데 이는 $\mathrm{SECI}(1.004)$ 가 효율성 향상에 미약한 기여를 하지만 $\mathrm{TCI}(0.898), \mathrm{PECI}(0.995)$ 로 인 해 전체적으로 비효율적인 결과가 나왔다. 한국의 경우 국가별 평균 $\mathrm{TFPI}$ 가 기간별 평균 $\mathrm{TFPI}$ 인 0.977보다 낮은 0.914로 분석 되었으며, 국가별 평균 생산성 지수에서 15 위를 차지하여 다른 $\mathrm{OECD}$ 국가 들 보다는 상대적으로 매우 낮은 효율성 증가가 이 루어졌다고 평가된다. 이는 앞서 분석한 정태적 분 석과는 사뭇 다른 결과라고 할 수 있다. 다시 말하 자면, 특정 년도에서는 한국의 효율성 점수가 높기 때문에 효율성 개선의 필요성이 제기되지 않았지만, 동태적 분석에서는 비교적 매우 낮은 TEPI 평가를 받았기 때문에 한국의 의료서비스 문제점을 파악하 고 이를 바로 잡아야 함을 알 수 있다. 한국의 의료 서비스의 MPI 점수가 낮은 이유는 5 년 동안 한국 의 TCI가 평균 0.914 로 생산성 하락에 크게 영향을 미쳤기 때문인데 이는 5년 동안 한국에서 지속적으 로 의료서비스와 관련한 기술의 퇴보가 이루어 졌 기 때문이다. 따라서 한국은 TCI를 높이기 위한 의
료서비스 프로세스 및 기술상의 혁신이 필요할 것 으로 판단된다.

〈표 8〉 국가별 평균 생산성 지수

\begin{tabular}{ccccccc}
\hline DMU & TECI & TCI & PECI & SECI & TFPI & 순위 \\
\hline \hline Australia & 1.064 & 0.932 & 1.000 & 1.064 & 0.991 & 9 \\
\hline Austria & 1.014 & 0.986 & 1.018 & 0.996 & 0.999 & 8 \\
\hline Belgium & 1.028 & 0.980 & 1.021 & 1.007 & 1.008 & 4 \\
\hline $\begin{array}{c}\text { Czech } \\
\text { Republic }\end{array}$ & 1.000 & 0.930 & 1.000 & 1.000 & 0.930 & 13 \\
\hline Estonia & 1.000 & 0.898 & 0.995 & 1.004 & 0.897 & 16 \\
\hline Finland & 1.042 & 0.961 & 1.041 & 1.001 & 1.001 & 7 \\
\hline Germany & 1.060 & 0.947 & 1.098 & 0.966 & 1.004 & 6 \\
\hline Hungary & 1.000 & 0.980 & 1.000 & 1.000 & 0.980 & 10 \\
\hline Israel & 1.000 & 0.933 & 1.000 & 1.000 & 0.933 & 12 \\
\hline Japan & 1.049 & 0.959 & 1.000 & 1.049 & 1.006 & 5 \\
\hline Korea & 1.000 & 0.914 & 1.000 & 1.000 & 0.914 & 15 \\
\hline Luxembourg & 1.049 & 0.969 & 1.015 & 1.033 & 1.017 & 3 \\
\hline Mexico & 1.000 & 0.924 & 1.000 & 1.000 & 0.924 & 14 \\
\hline Norway & 1.000 & 1.032 & 1.000 & 1.000 & 1.032 & 2 \\
\hline Poland & 1.000 & 0.964 & 1.000 & 1.000 & 0.964 & 11 \\
\hline Slovenia & 1.000 & 1.042 & 1.000 & 1.000 & 1.042 & 1 \\
\hline 평균 & 1.019 & 0.959 & 1.011 & 1.007 & 0.977 & \\
\hline & & & & & &
\end{tabular}




\section{5. 요약 및 결론}

현대사회에서는 삶의 질을 향상시키려는 노력이 지속되어 왔으며, 이를 위한 중요한 요소들 중 하나 가 의료 - 보건 서비스 분야이다. 그 동안 국내에서 의료기관의 서비스 효율성을 다룬 여러 가지 연구들 이 있었으나, 재무적 관점의 효율성을 목적으로 하 거나 의료서비스 생산성의 분석 대상을 국내 병원들 로만 한정하여 연구한 것이 대부분이었다. 따라서 본 연구는 의료서비스 생산성 분석의 대상을 국가적 차원으로 확장하여 한국의 의료서비스를 $\mathrm{OECD}$ 국 가들의 의료서비스와 비교분석하고자 하였다. 본 연구를 통해 $\mathrm{OECD}$ 국가간 의료서비스를 구성하는 투입 및 산출변수를 수집하여 $\mathrm{DEA}$ 와 MPI를 적용 함으로써 한국 의료서비스 시스템의 국제적 경쟁적 위상을 파악할 수 있었으며, 그 내용은 다음과 같이 요약될 수 있다.

먼저, 2005 2009년의 연도구간에 대해 CCR 모 형을 이용한 효율성 측정 결과, 효율적인 의료서비 스를 제공하는 나라는 헝가리, 이스라엘, 한국, 멕시 코, 노르웨이, 폴란드, 슬로베니아였으며 $\mathrm{BCC}$ 모형 의 결과는 오스트레일리아, 벨기에, 헝가리, 이스라엘, 일본, 한국 등이 높은 운영효율성을 달성하는 것으 로 나타났다. 전체적으로 한국의 경우 생산요소의 투입과 그에 따른 산출결과는 효율적인 것으로 파악 이 되어 국제적인 관점에서도 경쟁력이 있는 것으 로 파악되었다.

다음으로, 2005 2009년 사이의 연도구간에 대해 $\mathrm{MPI}$ 를 활용한 동태적 분석 결과 한국은 $\mathrm{OECD}$ 국 가별 평균 생산성 변화에 있어서 낮은 순위인 것으 로 파악되었다. 비록 $\mathrm{CCR}, \mathrm{BCC}$ 와 같은 정태적 모 형을 이용한 분석에서는 높은 효율성을 보여 개선 의 필요성이 제기되지 않았지만, 동태적 분석결과 를 통해 볼 때 일정량의 투입요소를 가지고 더 많은 산출요소를 생산 할 수 있는 기술상의 발전 정도가 퇴보했음을 알 수 있었다. 따라서 한국의 경우 의료 서비스 효율성 증대를 위한 의료서비스 프로세스의 혁신활동이 필요할 것으로 판단된다.
본 연구는 한국을 포함한 $\mathrm{OCDE}$ 국가들간의 의 료서비스 경쟁력을 분석한다는 의의를 지니나 몇 가지 한계점을 지닌다. 따라서 본 연구의 한계점과 그에 따른 추후 연구방향에 대해 논의하고 논문을 마무리 하고자 한다. 첫째, 본 연구에서 사용된 모 든 자료는 $\mathrm{OECD}$ 헬스 데이터를 바탕으로 하였기 때문에 자료가 없거나 미흡한 경우가 있었는데, 이 는 분석에 사용되는 투입 및 산출 요소 선정 시에 제약으로 작용하였다. 따라서 $\mathrm{OECD} 34$ 개국 중 16 개 나라만이 DMU로 선정되었으며 16 개국 중 10 개 국이 유럽에 속한 나라였기 때문에 국제적 비교 분 석 대상이 유럽에만 치우쳐 있다는 한계가 있다. 둘 째, 대상의 시간적 범위는 자료의 정확성과 수집가 능성을 고려하여 2005년부터 2009년까지로 두었는 데, 따라서 $\mathrm{MPI}$ 의 추이를 좀 더 폭넓게 하지 못하 였다는 아쉬움이 있었다. 따라서 추후 연구에서는 보다 정밀한 분석 및 시사점 도출을 위해서 보다 넓은 연도 범위에 대한 다양한 국가의 의료서비스 관련 자료들을 확보하여 보다 신뢰성 있는 효율성 분석을 수행해야 할 것이다. 다음으로 본 연구에서 는 의료서비스가 기대수명에 가장 큰 영향을 줄 것 이라는 가정을 기반으로 하였다. 그러나 국민의 기 대수명에는 식생활, 생활습관, 사회체육시설, 레크리 에이션 시설 등과 같은 복합적 요소들의 결과일 가 능성이 높다. 따라서 추후 연구에서는 의료활동을 통하여 국민들의 건강이 증진된 정도를 반영할 수 있도록 수술횟수 등의 자료를 확보하여 의료서비스 효율성 분석을 수행할 수 있을 것이다. 셋째, 본 연 구에서 사용한 투입요소 중 1 인당 의료지출 비용의 경우 단순히 US 달러를 활용하였다. 따라서 추후 연구에서는 국가별 시기별 화폐가치의 차이를 고려 하여 의료지출 비용을 보정하여 분석할 필요가 있 을 것이다. 마지막으로 본 연구에서는 효율성이라 는 하나의 측면만을 통하여 국가별 의료서비스 경 쟁력을 분석하였으며, 의료서비스 자체의 질적 측 면은 고려의 대상으로 삼지 않았다. 실제로 한국의 경우 다른 $\mathrm{OECD}$ 국가들에 비해 국민 1 인당 의료비 지출이나 의사의 수가 크게 적으나 환자당 연평균 
의사와의 접근횟수는 높게 나타났다. 이러한 요인 으로 인해 한국은 효율성 측면에서는 우수한 수준 으로 판단되나, 환자 개개인이 느끼는 의료서비스 의 질과는 양의 상관관계를 지닌다고 결론 내리기 는 어려울 것이다. 따라서 추후 연구에서는 의료서 비스의 질적인 측면을 측정할 수 있는 산출요소를 활용하여 질적인 측면을 포괄하는 효율성 분석을 수행할 필요가 있다.

\section{참고문헌}

[1] 고보선, "제주노인의 사회적 지지 유형특성과 주관적 삶의 질 결정요인에 관한 연구”, $\ulcorner$ 한국 노년학」, 제24권, 제2호(2004), pp.145-162.

[2] 김동진, “우리나라 성인의 의료이용의 형평성”, 「보건복지포럼」, 제176권(2011), pp.45-54.

[3] 김미경, “한국의료관광 참여의도의 영향요인에 관한 연구-일본과 중국의 잠재 수요자를 대상 으로”, 「관광연구」, 제 24 권, 제6호(2010), pp.213232.

[4] 김성호, 최태성, 이동원, 「효율성 분석 이론과 활용」, 서울경제경영, 2007.

[5] 김윤신, " $\mathrm{DEA}$ 를 이용한 종합병원의 효율성 평 가”, 「한국콘텐츠학회논문지」, 제9권, 제4호(2009), pp.299-312.

[6] 김정헌, "삶의 질 제고를 위한 보건의료복지지 표 체계구성과 과제”, 「복지행정논총」, 제 11 권, 제2호(2001), pp.31-53.

[7] 박경삼, 정홍식, 김윤태, "DEA 및 $\mathrm{DEA}$ 윈도 우분석을 이용한 대규모 종합병원의 시대별 경 영효율성 변화분석”, 「경영학연구」, 제 34 권, 제 1호(2005), pp.267-287.

[8] 박대식, 마상진, "도시와 농촌 주민의 삶의 질 지수화 방안 연구”, 「농촌경제」, 제 30 권, 제4호 (2007), pp.31-55.

[9] 신종각, “국립대학교병원의 효율성 및 생산성변 화 분석”, 「사회보장연구」, 제 22 권, 제4호(2006), pp.49-78.
[10] 심광식, 김재윤, "다중회귀분석을 이용한 DEA$\mathrm{AR}$ 모형 개발 및 국내 지방공사의 효율성 평 가”, 「한국경영과학회지」, 제37권, 제1호(2012), pp.29-43.

[11] 안영효, "DEA 와 Malmquist 생산성지수를 이 용한 한국의 주요 국가산업단지 운영 효율성 분 석”, 「한국지역개발학회지」, 제23권, 제5호(2011), pp.95-117.

[12] 양종현, 장동민, "국립대병원과 사립대병원의 효 율성 비교 분석”, ‘보건경제와 정책연구」, 제 15 권, 제2호(2009), pp.94-122.

[13] 이미숙, "한국 성인의 건강불평등-사회계층과 지 역 차이를 중심으로”, 「한국사회학」, 제 39 권, 제 6호(2005), pp.183-209.

[14] 이영범, “A Method of Adjusting Differential Operating Conditions in Measuring OrganizationaI Efficiency Using DEA”, 「한국정책학 회보」, 제12권, 제3호(2003), pp.119-143.

[15] 이정동, 오동현, 「효율성 분석이론 : DEA 자료 포락분석법」, IB Book, 2010.

[16] 장철영, 성도경, 최인규, "Post-DEA 를 활용한 지방의료원의 조직운영형태별 효율성 평가", 「한국행정논집」, 제19권, 제4호(2007), pp.11191146.

[17] 정가혜, "대학도서관의 $\mathrm{DEA}$ 분석", 한국경영과 학회 2009년 추계학술대회논문집, (2009), pp378389.

[18] 정금화, "농촌지역 의료서비스의 실태에 관한 연 구-경상북도를 중심으로”, 「복지행정논총」, 제 14권, 제1호(2004), pp.47-70.

[19] 정형선, 송양민, 이규식, "인구고령화와 의료비", 「보건경제와 정책연구」, 제 13 권, 제 1 호(2007), pp.95-116.

[20] 최종열, 김기석, 김도훈, "연안어업경영의 생산 효율성 분석”, 「한국경영과학회지」, 제 35 권, 제 3호(2010), pp.59-68.

[21] 탁기천, “의료기관의 종합적 품질경영 $(\mathrm{TQM})$ 에 관한 연구”, 「한국병원경영학회지」, 제8권, 제4 
호(2003), pp.26-58.

[22] Banker, R.D., A. Charnes, and W.W. Cooper, "Some models for estimating technical and scale inefficiencies in data envelopment analysis," Management science, Vol.30, No.9(1984), pp.1078-1092.

[23] Chang, H., "Determinants of hospital efficiency : the case of central government-owned hospitals in Taiwan," Omega, Vol.26, No.2 (1998), pp.307-317.

[24] Charnes, A., W.W. Cooper, and E. Rhodes, "Measuring the efficiency of decision making units," European journal of operational research, Vol.2, No.6(1978), pp.429-444.

[25] Chen, Y. and A.I. Ali, "DEA Malmquist productivity measure: New insights with an application to computer industry," European journal of operational research, Vol.159, No.1 (2004), pp.239-249.

[26] Cooper, W.W., L.M. Seiford, and J. Zhu, "Data envelopment analysis : History, mod- els, and interpretations," Handbook on data envelopment analysis, Vol.164(2011), pp.1-39.

[27] Farrell, M.J., "The measurement of productive efficiency," Journal of the Royal Statistical Society, Vol.120, No.3(1957), pp.253-290.

[28] Grosskopf, S., D. Margaritis, and V. Valdmanis, "The effects of teaching on hospital productivity," Socio-Economic Planning Sciences, Vol.35, No.3(2001), pp.189-204.

[29] Guyatt, G.H., D.H. Feeny, and D.L. Patrick, "Measuring health-related quality of life," $\mathrm{An}$ nals of internal medicine, Vol.118, No.8(1993), p.622.

[30] Mao, W. and W.W. Koo, "Productivity growth, technological progress, and efficiency change in Chinese agriculture after rural economic reforms : a DEA approach," China Economic Review, Vol.8, No.2(1997), pp.157-174.

[31] Molinero, C.M. and D. Woracker, "Data Envelopment Analysis," Or Insight, Vol.9, No.4 (1996), pp.22-28. 